\title{
Analyzing the Impacts of Vehicle Assist and Automation Systems on BRT
}

\author{
Matthew Hardy, Susannah Proper \\ Mitretek Systems
}

\begin{abstract}
This paper summarizes research that was conducted to develop an analysis framework with which to analyze the cost effectiveness of implementing Vehicle Assist and Automation (VAA) applications, a category of Intelligent Transportation System technologies, in Bus Rapid Transit (BRT) systems. Seven typical BRT operating scenarios were developed based upon the Federal Transit Administration's Characteristics of Bus Rapid Transit for Decision-Making report. The seven scenarios are representative of BRT service throughout the U.S. and are used to demonstrate which VAA applications will be cost effective within the context of real-world operating environments. The analysis examined overall benefits in terms of increased operating speed and reduced travel time compared to the cost of deploying VAA. Based upon the analysis framework, most of the operating scenarios show positive benefits over the life of the technology. The analysis also showed that deploying applications together (e.g., precision docking plus vehicle guidance) provided greater benefits since both applications use the same vehicle-based equipment. National impacts of implementing VAA applications were also analyzed based upon 75 BRT systems throughout the United States.
\end{abstract}




\section{Introduction}

In 2004, the U.S. Department of Transportation initiated a project examining the cost effectiveness of deploying Vehicle Assist and Automation (VAA) applications, a category of Intelligent Transportation System technologies (ITS), for Bus Rapid Transit (BRT) systems. This paper reports on the short-term financial and operational benefits identified as part of that larger analysis for two VAA applications, precision docking and vehicle guidance, applied to the following seven revenue service operating scenarios. These scenarios are defined in greater detail in the Characteristics of Bus Rapid Transit for Decision-Makers (CBRT) report (FTA, 2004).

- Suburban Collector-Buses operating in medium-density environment, often utilizing a line-haul right-of-way (ROW) with service to more dense urban areas.

- Urban Circulator-Buses operating in limited public use areas such as airports, shopping malls, downtown areas, or gated communities.

- Mixed Flow Lanes-Buses operating on the same lane(s) as regular traffic on arterials roads.

- Designated Arterial Lanes-Buses operating on a dedicated lane, indicated by a paint marking or rumble strip, adjacent to mixed traffic lanes.

- Roadway Shoulder Operations-Buses operating on a narrow ROW or operating on improved roadway shoulder. The same VAA application used for this scenario can be applied to improve effectiveness of operations in situations with reduced visibility of road edge due to inclement weather.

- At-Grade Transitway-Buses operating within a dedicated ROW but still interacting with surface traffic at signalize intersections.

- Fully Grade-Separated Exclusive Transitway-Operating in a dedicated ROW that is physically separated from other traffic lanes.

This analysis examined overall benefits of VAA applications in terms of increased operating speed and reduced travel time compared to the cost of the technology. No one measure was used to determine whether an operating scenario was cost effective. Rather, the measures were examined as a whole. The eight measures used to determine the cost effectiveness of a given operating scenario included Annual Bus Operating Cost Savings, Total Annualized Cost, Annualized User Benefits, Annualized Net Benefits, Benefit-Cost Ratio, Net Benefits After 1 Year, Years to Break-Even, and Net Benefits Over Life of Technology. 


\section{Analysis Framework}

The analysis framework used for this study is based upon the Screening for ITS (SCRITS) tool developed for the Federal Highway Administration ITS Joint Program Office, (FHWA 1999). SCRITS is a spreadsheet-based model that takes into account major system characteristics including the operating environment and costs, to determine quantitative impacts of deploying VAA applications. SCRITS generates a rough estimate in terms of impacts, costs, and benefits. The modified SCRITS tool provides only an order-of-magnitude estimate for a corridor rather than a detailed network-based assessment.

The analysis framework focuses on the reduction in vehicle running time due to VAA applications and benefits to the individual rider due to the reduction in travel time. Three critical parameters are needed for the model in order to derive the costs and benefits. First, an assessment is made regarding the potential impact of reducing bus travel time due to ITS technologies. It was important to factor out benefits caused by roadway geometry alone. For example, a vehicle operating on a grade-separated ROW has already achieved a significant reduction in running time compared to one operating in mixed traffic. The impact of any ITS on this operating scenario (such as transit signal priority) will have little impact on further reducing running time. Thus, the impact of ITS in affecting travel time is low. However, if a vehicle is currently operating on an at-grade transitway, the impact of ITS could be much higher. Based upon the CBRT and the ITS Benefit-Cost Database, the following ITS impact factors were used for each operating scenario (FHWA 2006):

- Suburban collector, urban circulator, mixed flowlLanes and designated arterial lane-50\%

- Roadway shoulder operations-30\%

- At-grade transitway-25\%

- Fully grade-separated exclusive transitway-15\%

The second parameter estimates the sole impact of VAA applications on running time as a percent of the total ITS impact. Due to the lack of operational systems and comprehensive evaluation data, there is limited empirical evidence that shows the impact of precision docking and vehicle guidance on reducing running time. However, the city of Rouen, France, has deployed precision docking technology and estimated a reduction in travel time of 4 percent to 5 percent (FHWA/FTA, 2005). Therefore, it was estimated that precision docking would result in a $5 \%$ reduction in running time. With regards to vehicle guidance, the city of Eindhoven, 
Netherlands, estimated some travel time improvement due to the vehicle guidance system being used. Rouen observed that vehicle guidance provided significant travel time improvements in areas that were difficult to maneuver. While no quantitative data exist on running time reduction due to vehicle guidance, for the purposes of this analysis, a 10 percent reduction in running time figure was used. Since these estimates are based on early deployers of VAA, the estimates may be conservative, and future VAA deployments with next generation technology might in fact provide greater benefits.

The third parameter is cost data, separated into technology costs and BRT system characteristic costs. Technology costs are presented in Table 1 and were derived from the VAA Systems for Transit Operations Synthesis White Paper (FHWA 2005). Transit System Characteristic costs are presented in Table 2 and are taken from the Characteristics of Bus Rapid Transit for Decision-Making report (FTA 2003). The CBRT report gives a range of costs for various BRT elements (running way, stations, vehicles, etc.) and which were segmented into low, medium, and high costs.

\section{Table 1. Technology Integration Costs}

\begin{tabular}{ll}
\hline Precision Docking & \\
Infrastructure & $\$ 4,000$ per station \\
Vehicle & $\$ 20,000$ per vehicle \\
Integration & $\$ 5,000$ per vehicle \\
Vehicle Guidance & \\
Infrastructure & $\$ 20,000$ per mile \\
Vehicle & $\$ 20,000$ per vehicle \\
Integration & $\$ 5,000$ per vehicle \\
\hline
\end{tabular}

Excluded from this analysis is the impact that VAA has on safety. Currently, the definition of VAA does not include collision warning and avoidance systems (FTA 2003). Initial deployments of VAA will be on systems operating in exclusive lanes, thus reducing potential bus-vs.-passenger-car incidents. However, it is not clear whether collision warning systems would ever be required as a critical component of VAA, since many of the VAA-equipped systems operational in Europe do not include them (FHWA/FTA 2005). VAA applications do not pose a new safety threat to passengers since the vehicle driver will continue to be a critical element 
Table 2 BRT System Characteristics Costs

\begin{tabular}{lrrr} 
Running Way (per mile) & Low & Medium & High \\
\hline Mixed Flow Lanes & $\$ 100,000$ & $\$ 195,000$ & $\$ 290,000$ \\
Designated Arterial & $\$ 2,500,000$ & $\$ 2,700,000$ & $\$ 2,900,000$ \\
At-Grade Transitway & $\$ 6,500,000$ & $\$ 8,350,000$ & $\$ 10,200,000$ \\
$\quad$ Fully Grade-Separated Transitway & $\$ 12,000,000$ & $\$ 36,000,000$ & $\$ 60,000,000$ \\
Stations (per station) & & & \\
Simple Stop & $\$ 15,000$ & $\$ 17,500$ & $\$ 20,000$ \\
Enhanced Stop & $\$ 25,000$ & $\$ 30,000$ & $\$ 35,000$ \\
Designated Station & $\$ 150,000$ & $\$ 1,325,000$ & $\$ 2,500,000$ \\
Intermodal Terminal or Transit Center & $\$ 5,000,000$ & $\$ 12,500,000$ & $\$ 20,000,000$ \\
Vehicles (per vehicle) & & & \\
Conventional Standard & $\$ 300,000$ & $\$ 325,000$ & $\$ 350,000$ \\
Stylized Standard & $\$ 300,000$ & $\$ 325,000$ & $\$ 350,000$ \\
Conventional Articulated & $\$ 500,000$ & $\$ 550,000$ & $\$ 600,000$ \\
Stylized Articulated & $\$ 630,000$ & $\$ 790,000$ & $\$ 950,000$ \\
Specialized BRT Vehicles & $\$ 950,000$ & $\$ 1,275,000$ & $\$ 1,600,000$ \\
\hline
\end{tabular}

in the operation of the VAA-equipped vehicle and will remain responsible for ensuring that the vehicle avoids hitting passengers and obstacles.

\section{Operating Scenario Analysis}

Each scenario analysis includes a summary of the system characteristics that were used as inputs for the analysis and a brief description of how the VAA applications would be used. The descriptions and data for the operating scenarios were initially derived from the Characteristics of Bus Rapid Transit for Decision-Making report and were later refined with information from current operations of VAA and/or BRT systems (FTA 2004). System characteristics include running way, station, and vehicle type. Operating characteristics include average operating speed, bus frequency, number of daily passengers, average passenger trip length, elasticity of demand, value of time, operating cost per bus route hour and daily vehicle trips in corridor. 


\section{Suburban Collector}

This scenario represents a medium-density environment operating at lower speeds. The only appropriate VAA application would be precision docking to better facilitate passenger boarding and alighting, which could be particularly helpful for boarding passengers with physical limitations. Operational models for current suburban collectors typically feature relatively fixed routes, or free travel within a small fixed perimeter.

A suburban collector with VAA does not currently exist; therefore, a hypothetical system was developed and modeled based on a proposed system in Florida called FlexBRT. This system would operate on mixed flow lanes and require 16 buses. ITS technologies would have a 50 percent impact on travel time and the precision docking application would account for 5 percent of this impact. The results of this scenario are presented in Table 3.

Table 3. Suburban Collector Impacts

\begin{tabular}{|l|r|l|r}
\hline Cost Savings & & Benefits & \\
\hline Annualized Operating Cost Savings & $\$ 251$ & Benefit/Cost Ratio & 0.24 \\
\hline $\begin{array}{l}\text { Total Annualized Cost of VAA } \\
\text { equipment }\end{array}$ & $\$ 365,964$ & Net Benefits After 1 Year & $-\$ 2,171,915$ \\
\hline Annualized User Benefits & $\$ 86,049$ & Years to Break-Even & -7 \\
\hline Annualized Net Benefits & $-\$ 279,664$ & $\begin{array}{l}\text { Net Benefits Over Life of } \\
\text { Technology }\end{array}$ & $-\$ 4,131,322$ \\
\hline
\end{tabular}

The use of precision docking in this operating scenario appears not to be warranted. Based upon a technology service life of eight years, the use of the technology never provides a net benefit. Rather, the overall cost to install the technology far outweighs the benefits derived. One reason for this is that the projected ridership is low at 4,100 daily passengers. Additionally, the cost savings are very small, consisting of some minor savings on travel time at the BRT stop. If the number of passengers increased, the overall travel time savings could be more and the net benefits could increase. However, the 4,000 ridership level is a typical kind of service. Even if the ridership doubled, to 8,000 per day, the VAA applications would probably still not be cost effective. 


\section{Urban Circulator}

This scenario represents a high-density environment, such as the downtown circulator bus systems currently operating in major cities throughout the U.S. Circulator vehicles with VAA applications have been tested in both Europe and Japan, not so much for their projected cost or safety benefits, but as a low-risk way to demonstrate a new technology. Currently, the only two urban circulator systems operating with VAA applications include an amusement park in Japan and a highdensity business park in Rotterdam, Netherlands. The urban circulator systems that have been deployed with VAA so far are more typical of a free "people mover" operation, not revenue service public transport, but it is too early to predict the future trend for this operating scenario.

Urban circulator systems typically operate on some type of dedicated facility, either for exclusive use by the circulator system or for use by transit vehicles in general. The use of precision docking would be advantageous to better facilitate boarding and alighting passengers. It would be relatively simple to deploy vehicle guidance on a dedicated facility, which would reduce the need for a separate collision warning system to account for various types of obstacles and hazards from other vehicles and pedestrians.

The urban circulator system used for this analysis is modeled after an operational system in Orlando called the LYMMO. The system operates on an at-grade transitway and currently does not include any VAA applications. This operating scenario analyzed the impacts of adding precision docking and vehicle guidance, where ITS would have a 50 percent impact on travel time and VAA would account for 15 percent of this impact. The results of this scenario are presented in Table 4.

The urban circulator system was analyzed first using only precision docking and then precision docking and vehicle guidance. In both instances, the results are favorable. The use of precision docking generates a $\mathrm{B} / \mathrm{C}$ ratio of 2.65 , two years to break-even, and positive net benefits over the expected life of technology. Adding vehicle guidance applications further increases the benefits. The positive results can be attributed primarily to the reduction in travel time and to the higher ridership. 
Table 4. Urban Circulator Impacts

\begin{tabular}{|l|r|r|l|r|r|}
\hline Cost Savings & \multicolumn{1}{|c|}{$\begin{array}{c}\text { Precision } \\
\text { Docking }\end{array}$} & $\begin{array}{r}+ \text { Vehicle } \\
\text { Guidance }\end{array}$ & \multicolumn{1}{|c|}{ Benefits } & \multicolumn{1}{c|}{$\begin{array}{c}\text { Precision } \\
\text { Docking }\end{array}$} & $\begin{array}{c}\text { + Vehicle } \\
\text { Guidance }\end{array}$ \\
\hline $\begin{array}{l}\text { Annualized Operating Cost } \\
\text { Savings }\end{array}$ & $\$ 1,847$ & $\$ 5,540$ & Benefit/Cost Ratio & 2.65 & 7.28 \\
\hline Total Annualized Cost & $\$ 91,748$ & $\$ 100,268$ & $\begin{array}{l}\text { Net Benefits After 1 } \\
\text { Year }\end{array}$ & $-\$ 142,472$ & $\$ 275,560$ \\
\hline Annualized User Benefits & $\$ 243,276$ & $\$ 729,828$ & Years to Break-Even & 2 & 1 \\
\hline Annualized Net Benefits & $\$ 153,274$ & $\$ 635,099$ & $\begin{array}{l}\text { Net Benefits Over Life } \\
\text { of Technology }\end{array}$ & $\$ 1,221,279$ & $\$ 5,941,598$ \\
\hline
\end{tabular}

\section{Mixed Flow Lanes}

Mixed flow lane operations are typical of many transit systems in the U.S where transit buses operate in the same lanes as regular traffic on limited access highways, interstates, arterials, or local streets. Since there is no dedicated ROW, only precision docking is analyzed because, in the short term, it is unlikely vehicle guidance would be sufficiently mature to permit operations in mixed traffic.

The mixed flow lane operating scenario is modeled after an existing BRT system in Oakland, California, called the San Pablo RAPID. The operating scenario analyzed the impact of deploying precision docking at 22 stations where all vehicles would be equipped with the appropriate vehicle-based components. ITS would have a 50 percent impact on travel time and the precision docking would account for 5 percent of this impact. The results of this scenario are presented in Table 5.

The impact of installing precision docking on transit vehicles operating in mixed flow lanes is significant. Benefits are derived primarily through the reduction of dwell time at transit stops which reduces the overall running time of the bus, thus increasing the operating speed. In this scenario, the $\mathrm{B} / \mathrm{C}$ ratio is 2.43 , indicating benefits are greater than costs, and it would take approximately two years to realize net benefits. Over the estimated eight year service life of the technology, net benefits would be almost $\$ 900,000$. In this case, the higher ridership provided significant benefits even though only precision docking was used.

\section{Designated Arterial Lane}

U.S. cities are increasingly turning to designated arterial lanes for transit operations in order to improve transit service. However, many localities are encountering barriers to creating a designated lane due to ROW constraints. Vehicle guid- 
Table 5. Mixed Flow Lanes Impacts

\begin{tabular}{|l|r|l|r|}
\hline \multicolumn{2}{|l|}{ Cost Savings } & Benefits \\
\hline Annualized Operating Cost Savings & $\$ 4,813$ & Benefit/Cost Ratio & 2.43 \\
\hline Total Annualized Cost & $\$ 106,446$ & Net Benefits After 1 Year & $\$ 185,415$ \\
\hline Annualized User Benefits & $\$ 259,031$ & Years to BreakEven & 2 \\
\hline Annualized Net Benefits & $\$ 157,398$ & $\begin{array}{l}\text { Net Benefits Over Life of } \\
\text { Technology }\end{array}$ & $\$ 882,682$ \\
\hline
\end{tabular}

ance would enable vehicles to operate safely within a narrower lane width, thus reducing the infrastructure costs and design constraints of creating a designated lane in an already crowded environment. Vehicle guidance could also enable transit agencies to carve out a narrow transit lane within the existing ROW.

The designated arterial lane system used for this analysis is modeled after the Silver Line in Boston. The system operates on a dedicated lane that is striped and signed to differentiate it from the other travel lanes for 4.7 miles, and in mixed flow lanes for 3 miles. The operating scenario analyzed the impact of deploying precision docking at all 20 stations on the 7.3 mile route, and vehicle guidance along the 4.7 miles of dedicated lane. ITS technology would have a 50 percent impact on travel time and precision docking and vehicle guidance would account for 15 percent of this impact. The results of this scenario are presented in Table 6.

The designated arterial lane operating scenario was analyzed first using only precision docking and then precision docking and vehicle guidance. In both instances, the results are favorable. The use of precision docking generates a $\mathrm{B} / \mathrm{C}$ ratio of 2.90, two years to break-even, and positive net benefits over the life of technology. Adding vehicle guidance further increases the benefits. The $B / C$ ratio more than doubles, benefits would be seen within the first year of deploying the technology, and overall net benefits would increase by nearly five-fold. This scenario illustrates the significant benefits that VAA can provide, even on a relatively short BRT route.

\section{Roadway Shoulder Operations}

Roadway shoulder operations occur when a transit agency operates buses on a roadway shoulder in order to bypass congested areas. Currently, a few transit agencies operate buses on a bus-only shoulder lane, although not at full highway speeds. In all instances, transit agencies have teamed with the respective state and local DOTs to ensure that the existing roadway shoulder is suitable for buses to 
Table 6. Designated Arterial Lane Impacts

\begin{tabular}{|l|r|r|l|r|r|}
\hline Cost Savings & $\begin{array}{c}\text { Precision } \\
\text { Docking }\end{array}$ & $\begin{array}{l}\text { + Vehicle } \\
\text { Guidance }\end{array}$ & Benefits & $\begin{array}{c}\text { Precision } \\
\text { Docking }\end{array}$ & $\begin{array}{c}+ \text { Vehicle } \\
\text { Guidance }\end{array}$ \\
\hline $\begin{array}{l}\text { Annualized Operating Cost } \\
\text { Savings }\end{array}$ & $\$ 2,509$ & $\$ 7,528$ & Benefit/Cost Ratio & 2.90 & 7.57 \\
\hline Total Annualized Cost & $\$ 105,110$ & $\$ 120,808$ & $\begin{array}{l}\text { Net Benefits After 1 } \\
\text { Year }\end{array}$ & $-\$ 130,275$ & $\$ 369,697$ \\
\hline Annualized User Benefits & $\$ 304,835$ & $\$ 914,505$ & Years to Break-Even & 2 & 1 \\
\hline Annualized Net Benefits & $\$ 202,234$ & $\$ 801,225$ & $\begin{array}{l}\text { Net Benefits Over Life } \\
\text { of Technology }\end{array}$ & $\$ 1,267,800$ & $\$ 5,925,577$ \\
\hline
\end{tabular}

operate on. In a few cases where the roadway shoulders do not meet minimum design requirements, DOTs have made improvements to the roadway shoulder. Typically, buses only use the roadway shoulder during operating peak periods when congestion is present.

Minnesota's Metro Transit found considerable operating benefits in creating a bus-only shoulder lane (without VAA applications) (Metro Transit 2003). Passengers perceived that their trip on the shoulder was 15 minutes faster than driving in mixed traffic, although, in reality, their trip was only 8 minutes faster. There were also issues with "jealous motorists" in passenger cars blocking the bus lane or illegally driving in the bus lane, which has also been reported with similar operations in Europe. Anecdotal evidence suggests that operating buses in these conditions is stressful for bus drivers and that the use of vehicle guidance technologies could significantly reduce this stress especially during times of inclement weather, when congestion is at its worst and buses would derive the greatest benefit from using the roadway shoulder.

The roadway shoulder operation scenario is modeled after the Phoenix RAPID, which operates in both mixed flow lanes and designated arterial lanes (on the shoulder). The analysis included the impact of deploying vehicle guidance technology along the 43.8 miles of designated arterial lanes (roadway shoulder) on which the RAPID operates. ITS would have a 30 percent impact on travel time and the vehicle guidance would account for 10 percent of this impact. The results of this scenario are presented in Table 7.

The table clearly shows that, for this specific scenario using data based on realworld operations in Phoenix, implementing vehicle guidance would not be cost effective. It is possible that VAA would show benefit in a similar roadway shoulder 
Table 7. Roadway Shoulder Operations Impacts

\begin{tabular}{|l|r|l|r|}
\hline \multicolumn{2}{|l|}{ Cost Savings } & Benefits \\
\hline Annualized Operating Cost Savings & $\$ 57,965$ & Benefit/Cost Ratio & 0.88 \\
\hline Total Annualized Cost & $\$ 338,242$ & Net Benefits After 1 Year & $-\$ 1,767,851$ \\
\hline Annualized User Benefits & $\$ 296,391$ & Years to Break-Even & -41 \\
\hline Annualized Net Benefits & $\$ 16,114$ & $\begin{array}{l}\text { Net Benefits Over Life of } \\
\text { Technology }\end{array}$ & $-\$ 2,060,808$ \\
\hline
\end{tabular}

operational scenario with different numbers for passenger demand, operating speed, length, etc. There may be other benefits that were not taken into account, particularly ROW costs and reducing driver stress. The cost-savings for ROW acquisition, which were not taken into account in this calculation, could be considerable. In some situations, the use of vehicle guidance may be the key element that allows for the use of a narrow lane. Analyzing that type of scenario is difficult since land values vary considerably across the U.S. Vehicle guidance may reduce driver stress while operating on a narrow lane. However, this analysis framework was not designed to account for perceived human factors benefits.

\section{At-Grade Transitway}

In this scenario, transit buses operate on a dedicated transitway where only transit vehicles are permitted. The transitway is physically separated from other traffic lanes but is not entirely grade separated. Similar to the designated lane scenario, a benefit of vehicle guidance is the ability to have a smaller lane width thus improving the possibility of creating a new at-grade transitway in an already crowded environment. There are operational systems in Europe, Australia, and Japan that use at-grade transitways with vehicle guidance, though many of these systems use a mechanical guideway technology requiring specially designed lanes.

The at-grade transitway system analyzed here is modeled after South Miami-Dade Busway in Miami, Florida. The system operates on a dedicated transitway built adjacent to U.S. 1. The operating scenario analyzed the impact of deploying precision docking at all 23 stations and vehicle guidance along the entire 8 mile route. ITS would have a 25 percent impact on travel time and VAA applications would account for 15 percent of this impact. The results of this scenario are presented in Table 8. 
Table 8. At-Grade Transitway Impacts

\begin{tabular}{|l|r|r|l|r|r|}
\hline Cost Savings & $\begin{array}{c}\text { Precision } \\
\text { Docking }\end{array}$ & $\begin{array}{l}\text { + Vehicle } \\
\text { Guidance }\end{array}$ & Benefits & $\begin{array}{c}\text { Precision } \\
\text { Docking }\end{array}$ & $\begin{array}{c}\text { + Vehicle } \\
\text { Guidance }\end{array}$ \\
\hline $\begin{array}{l}\text { Annualized Operating Cost } \\
\text { Savings }\end{array}$ & $\$ 1,046$ & $\$ 3,137$ & Benefit/Cost Ratio & 1.25 & 3.75 \\
\hline Total Annualized Cost & $\$ 107,114$ & $\$ 107,114$ & $\begin{array}{l}\text { Net Benefits After 1 } \\
\text { Year }\end{array}$ & $-\$ 315,162$ & $-\$ 47,258$ \\
\hline Annualized User Benefits & $\$ 133,952$ & $\$ 401,856$ & Years to Break-Even & 13 & 1 \\
\hline Annualized Net Benefits & $\$ 27,884$ & $\$ 297,879$ & $\begin{array}{l}\text { Net Benefits Over Life } \\
\text { of Technology }\end{array}$ & $-\$ 127,295$ & $\$ 2,015,940$ \\
\hline
\end{tabular}

The at-grade transitway operating scenario was analyzed first using only precision docking, then adding vehicle guidance. Only the second technology package demonstrated positive benefits, indicating that precision docking alone will not provide benefits. In other words, precision docking must be combined with vehicle guidance to offset the cost of installing the technology. Since this system has many stations (23), there is a larger capital cost associated with the technology when using precision docking alone. Incorporating vehicle guidance will help to offset that initial capital cost. Of course, higher ridership, which may provide greater benefits, would improve the analysis even more.

\section{Fully Grade-Separated Exclusive Transitway}

In this scenario, transit buses operate in exclusive lanes separated by grade, concrete barriers, or other devices. This has similar benefits to narrow lane, at-grade transitway or shoulder operation, but with significantly greater infrastructure costs. Most current operations of VAA applications use an at-grade transitway, not a fully grade-separated exclusive transitway. There might be additional safety or mobility benefits to using fully grade-separated lanes versus an at-grade transitway, depending on the signalization issues, but with VAA applications, there are no real differences in terms of VAA technology required. A separated lane with no traffic signals would be faster than a separated lane where buses must stop at signalized intersections. A fully grade-separated lane would remove all possibility of SOV motorists encroaching or conflicting with the VAA-equipped bus, but at significant infrastructure cost.

Both precision docking and vehicle guidance (as well as full automation in the future) could be used for this scenario. Similar to the designated lane scenario, a 
benefit of vehicle guidance is the ability to have a smaller lane width, thus reducing the infrastructure cost and "footprint" for the transitway itself. Another potential benefit not factored into this analysis is that a fully grade-separated exclusive transitway would likely meet the eligibility requirements for a fixed guideway "New Start"; thus, there might be another funding mechanism to pay for the technology. However, the drawbacks are great: costs would be in the range of $\$ 12$ to 30 million per lane mile for aerial installations, and $\$ 60$ to 105 million for underground installations (FTA 2004).

The fully grade-separated exclusive transitway system is modeled after the West Busway in Pittsburgh. The system operates on a dedicated transitway for 4.6 miles and in mixed flow lanes for 0.4 miles. The operating scenario analyzed the impact of deploying precision docking at all 10 stations, with vehicle guidance along 4.6 miles of the dedicated transitway portion of the route. ITS would have a 15 percent impact on travel time, with precision docking and vehicle guidance accounting for 20 percent of this impact. The results of this scenario are presented in Table 9.

\section{Table 9. Fully Grade-Separated Exclusive Transitway Impacts}

\begin{tabular}{|l|r|r|l|r|r|}
\hline Cost Savings & $\begin{array}{c}\text { Precision } \\
\text { Docking }\end{array}$ & $\begin{array}{l}\text { + Vehicle } \\
\text { Guidance }\end{array}$ & Benefits & $\begin{array}{c}\text { Precision } \\
\text { Docking }\end{array}$ & $\begin{array}{c}\text { + Vehicle } \\
\text { Cuidance }\end{array}$ \\
\hline $\begin{array}{l}\text { Annualized Operating Cost } \\
\text { Savings }\end{array}$ & $\$ 1,009$ & $\$ 3,027$ & Benefit/Cost Ratio & 1.66 & 4.98 \\
\hline Total Annualized Cost & $\$ 110,955$ & $\$ 110,955$ & $\begin{array}{l}\text { Net Benefits After 1 } \\
\text { Year }\end{array}$ & $-\$ 291,809$ & $\$ 76,484$ \\
\hline Annualized User Benefits & $\$ 184,146$ & $\$ 552,439$ & Years to Break-Even & 5 & 1 \\
\hline Annualized Net Benefits & $\$ 74,200$ & $\$ 444,511$ & $\begin{array}{l}\text { Net Benefits Over Life } \\
\text { of Technology }\end{array}$ & $\$ 220,530$ & $\$ 3,166,870$ \\
\hline
\end{tabular}

The fully grade separated exclusive transitway operating scenario was analyzed first using only precision docking, then adding vehicle guidance. The use of precision docking and vehicle guidance generates a $\mathrm{B} / \mathrm{C}$ ratio of 4.98 , one year to breakeven, and significant net benefits over the life of technology. The net benefits are considerable, particularly for the vehicle guidance scenario. The main benefit is significantly reduced passenger travel time. For new systems with large ROW acquisition costs, additional cost savings would be gained since a narrower lane could be used. 


\section{Summary and Implications}

A summary comparing each operating scenario is presented in Table 10 in the order they were discussed. Overall, most of the operating scenarios produced a positive $B / C$ ratio, generated benefits within three years of deploying the technology, and generated positive benefits over the life of the technology. Based upon these criteria, five of the seven operating scenarios produced an overall positive benefit and are ranked as follows beginning with greatest level of benefits: 1) designated arterial lanes, 2) urban circulator, 3) fully grade-separated exclusive transitway, 4) at-grade transitway and, 5) mixed flow lanes.

The designated arterial, urban circulator, and fully grade-separated exclusive transitway all provide similar benefits in both type and magnitude. Essentially, these three scenarios are subtle variations of a single scenario of operating VAAequipped buses in lanes which are in some way separated from the flow of passenger car traffic. This separation permits the safe use of VAA in the immediate future. Mixed flow lanes ranked lower since the only VAA application appropriate at this time is precision docking. Therefore, mixed flow lanes are unable to take advantage of leveraging the VAA technology already installed on the vehicle for vehicle guidance as well.

Two scenarios were not able to demonstrate benefit from VAA. In the case of the suburban collector, ridership is not sufficient to generate significant cumulative travel time savings for passengers. In the case of shoulder operations, the bus is already providing faster travel time by operating on the shoulder; the addition of lane guidance does not provide significant extra travel time benefit in that case, using the numbers based on real world operations. However, there may be significant benefits in both operating scenarios for reduced ROW costs and improved driver comfort, neither of which could be accurately quantified for this analysis. For roadway shoulder operations, the most important benefit may be the ability to operate on the shoulder when it is most needed-during inclement weatherwhich is not captured in this analysis.

It is also important to understand the context in which VAA applications will be deployed and the commercial viability of developing the technology. To this end, those BRT sites either operating, under construction or in the planning stages were documented and classified according to the operating scenarios and are shown in Table 11. Data regarding the sites were gathered from various web resources. 
Table 10. Operating Scenario Analysis

\begin{tabular}{|c|c|c|c|c|c|c|c|}
\hline & 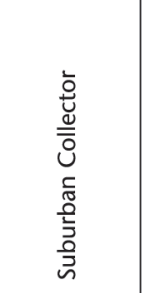 & 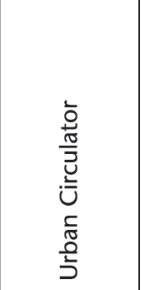 & 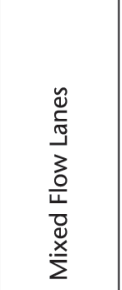 & 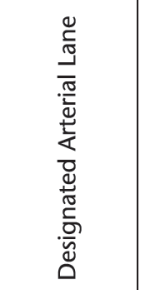 & 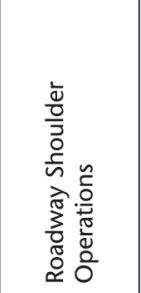 & 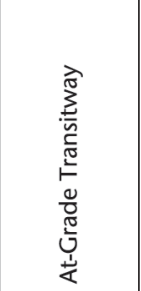 & 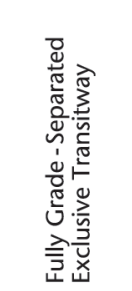 \\
\hline \multicolumn{8}{|l|}{ Cost Savings } \\
\hline $\begin{array}{l}\text { Annualized } \\
\text { Operating Cost } \\
\text { Savings }\end{array}$ & $\$ 251$ & $\$ 5,540$ & $\$ 4,813$ & $\$ 7,528$ & $\$ 57,965$ & $\$ 3,137$ & $\$ 3,027$ \\
\hline $\begin{array}{l}\text { Total Annualized } \\
\text { Cost }\end{array}$ & $\$ 365,964$ & $\$ 100,268$ & $\$ 106,446$ & $\$ 120,808$ & $\$ 338,242$ & $\$ 107,114$ & $\$ 110,955$ \\
\hline $\begin{array}{l}\text { Annualized User } \\
\text { Benefits }\end{array}$ & $\$ 86,049$ & $\$ 729,828$ & $\$ 259,031$ & $\$ 914,505$ & $\$ 296,391$ & $\$ 401,856$ & $\$ 552,439$ \\
\hline $\begin{array}{l}\text { Annualized Net } \\
\text { Benefits }\end{array}$ & $-\$ 279,664$ & $\$ 635,099$ & $\$ 157,398$ & $\$ 801,225$ & $\$ 16,114$ & $\$ 297,879$ & $\$ 444,511$ \\
\hline \multicolumn{8}{|l|}{ Benefits } \\
\hline Benefit/Cost Ratio & 0.24 & 7.28 & 2.43 & 7.57 & 0.88 & 3.75 & 4.98 \\
\hline $\begin{array}{l}\text { Net Benefits } \\
\text { After } 1 \text { Year }\end{array}$ & $-\$ 2,171,915$ & $\$ 275,560$ & $-\$ 185,415$ & $\$ 369,697$ & $-\$ 1,767,851$ & $\$ 47,258$ & $\$ 76,484$ \\
\hline $\begin{array}{l}\text { Years to } \\
\text { Break-Even }\end{array}$ & -7 & 1 & 2 & 1 & -41 & 1 & 1 \\
\hline $\begin{array}{l}\text { Net Benefits Over } \\
\text { Life of Technology }\end{array}$ & $-\$ 4,131,322$ & $\$ 5,941,598$ & $\$ 882,682$ & $\$ 5,925,577$ & $-\$ 2,060,808$ & $\$ 2,015,940$ & $\$ 3,166,870$ \\
\hline Ranking & 6 & 2 & 5 & 1 & 7 & 4 & 3 \\
\hline
\end{tabular}

The analysis showed that five of the seven operating scenarios demonstrated a positive benefit based upon the criteria. Therefore, 21 of the 27 systems in operation (78\%) may benefit from the use of VAA applications. Furthermore, all of the BRT systems in construction and 42 of the 46 systems in the planning stage (91\%) may benefit from VAA applications. This means that 65 of the 75 sites identified (87\%) may derive some benefit from the addition of VAA applications. 
Table 11. BRT Operating Scenario Summary

\begin{tabular}{|l|c|c|c|c|c|}
\hline \multicolumn{1}{|c|}{ Operating Scenario } & $\begin{array}{c}+ \text { or } \\
\text { Benefits }\end{array}$ & Operating & Construction & Planning & Total \\
\hline Suburban Collector & - & 2 & 0 & 1 & 3 \\
\hline Urban Circulator & + & 1 & 0 & 1 & 2 \\
\hline Mixed Flow Lanes & + & 5 & 0 & 21 & 26 \\
\hline Designated Arterial Lane & + & 2 & 1 & 9 & 12 \\
\hline Roadway Shoulder Operations & - & 4 & 0 & 3 & 7 \\
\hline At-Grade Transitway & + & 4 & 1 & 4 & 9 \\
\hline $\begin{array}{l}\text { Fully Grade -Separated Exclusive } \\
\text { Transitway }\end{array}$ & + & 9 & 0 & 7 & 16 \\
\hline Total & & 27 & 2 & 46 & 75 \\
\hline
\end{tabular}

As seen with some of the scenarios, benefits are sensitive to both ridership estimates and the value of time for the riders. A system with high ridership would probably generate greater benefits over a similar system with fewer riders. Yet, higher ridership does not necessarily equate to greater benefits. ROW length, number of stations and number of vehicles will impact the overall infrastructure cost associated with deploying VAA. These costs would then impact the overall cost/benefit breakeven point. In addition, there might be considerable local variation in the sensitivity of this analysis to ridership estimates and infrastructure costs.

The results of this analysis must be tempered with the knowledge that there is very little operational data to currently support some of the input data required by the model. Operational systems in Europe and Japan have demonstrated that the technology can be used for revenue service operations; yet very few comprehensive system evaluations have been conducted examining cost savings, ridership increases, travel time savings, or other possible benefits. Future research should address this issue as U.S. transit agencies begin to deploy VAA applications.

Overall, it is significant that this order-of-magnitude benefit estimation and planning exercise has been successfully completed and is available for others to use. 
Using empirical data for some benefits and rather conservative estimates for others, the model demonstrated positive impacts due to VAA applications for most BRT scenarios. It may now be appropriate for the many localities planning BRT systems to consider adding VAA applications to their projects.

\section{Acknowledgements}

This paper reports on analysis performed as part of the U.S. DOT ITS JPO Tier II research project called Multimodal Vehicle Assist and Automation Systems. More information regarding this project and final reports developed as part of this research are available at http://www.its.dot.gov.

\section{References}

BRT Sites identified via http://www.fta.dot.gov and http://gobrt.org. Accessed April 2005.

Federal Highway Administration. 1999. ITS Joint Program Office. Screening Tool for ITS (SCRITS). Available at http://www.its.dot.gov. Washington, D.C.

Federal Highway Administration. ITS Joint Program Office. 2005 Multimodal Vehicle Assist and Automation: VAA Systems for Transit Operations Synthesis White Paper. Washington, D.C.

Federal Highway Administration. 2006. ITS Joint Program Office. ITS Benefit-Cost Database. Available at http://www.benefitcost.its.dot.gov. Washington, D.C.

Federal Highway Administration and Federal Transit Administration. 2005. ITS Joint Program Office. Lane Assist Systems in Europe: Report on Technical Visit to Europe on Transit Lane Assist Technologies. Washington, D.C.

Federal Transit Administration. 2003. Office of Research, Demonstration and Innovation. Bus Rapid Transit Lane Assist Technology Systems, Volume 1, Technology Assessment. Washington, D.C.

Federal Transit Administration. 2004. Office of Research, Demonstration and Innovation. Characteristics of Bus Rapid Transit for Decision-Making (CBRT). Washington, D.C. 


\section{About the Authors}

MATTHEW HARDY (matthew.hardy@mitretek.org) is a Lead Transportation Engineer at Mitretek Systems based in Washington, D.C. He is a graduate of George Mason University in Fairfax, Virginia where he earned a Bachelor of Science in Urban Systems Engineering and a Master of Science in Transportation Policy, Operations and Logistics. He is currently pursuing a Ph.D. in Public Policy. He has conducted extensive research in the application of ITS technologies to Bus Rapid Transit Systems and Vehicle Assist and Automation systems for transit applications. He was co-author of the Characteristics of Bus Rapid Transit for Decision-Making report. He is a current member of the TRB Joint Subcommittee on Intersection Design, Safety and Operations, and the committee on Vehicle-Highway Automation.

SUSANNAh Proper (sproper@mitretek.org) is a Principal Engineer at Mitretek Systems based in Washington, D.C. She is a graduate of Northwestern University in Evanston, Illinois, with a Bachelor of Science in Economics and a graduate of the University of Maryland, College Park, with a Master of Public Policy degree. Past work has included advanced vehicle technologies, systems engineering, GPS modernization analysis, domestic and international standards, geospatial integration, human factors, economic and policy analysis, and advanced vehicle control and safety systems. 